\title{
Simulação e validação de um modelo matemático para o perfil de temperatura do milho armazenado em silo-bolsa
}

\section{Simulation and validation of a mathematical model for temperature profile of corn stored in silo bag}

\author{
Roberta Martins NOGUEIRA ${ }^{1 *}$; Bruna Bono HERRERA ${ }^{2}$; Solenir RUFFATO ${ }^{3}$; \\ Evaldo Martins PIRES ${ }^{4}$
}

${ }^{1}$ Doutora em Engenharia Agrícola; Universidade Federal de Mato Grosso - Campus Universitário de Sinop; Instituto de Ciências Agrárias e Ambientais; Av Alexandre Ferronato, 1200, Setor Industrial, Sinop, MT; roberta_nogueira@ufmt.br

${ }^{2}$ Estudande de Engenharia Agrícola e Ambiental; Universidade Federal de Mato Grosso - Campus Universitário de Sinop; Instituto de Ciências Agrárias e Ambientais; brunna_herrera@hotmail.com

${ }^{3}$ Doutora em Engenharia Agrícola; Universidade Federal de Mato Grosso - Campus Universitário de Sinop; Instituto de Ciências Agrárias e Ambientais; sruffato@ufmt.br

${ }^{4}$ Doutor em Entomologia; Universidade Federal de Mato Grosso - Campus Universitário de Sinop; Instituto de Ciências Naturais, Humanas e Sociais; evaldo@ufmt.br

Recebido em: 30-10-2013; Aceito em: 12-06-2014

\begin{abstract}
Resumo
O aumento da produção de grãos e o déficit da capacidade estática de armazenamento têm obrigado alguns produtores a estocar milho safrinha a céu aberto, principalmente no Estado do Mato Grosso. $\mathrm{O}$ uso de silos-bolsas é uma alternativa de curto prazo ao armazenamento tradicional em nível de fazenda. Sabendo-se que o comportamento da temperatura dos grãos durante a armazenagem é fator preponderante para sua qualidade final, objetivou-se simular numericamente, por meio da técnica da dinâmica de fluidos computacional (CFD), a distribuição da temperatura de uma massa de milho armazenada durante quatro meses em silo-bolsa e validar os dados encontrados com a medição em condições reais. As simulações foram realizadas com base nos dados de temperatura média do ar da região $\left(24{ }^{\circ} \mathrm{C}\right)$ e temperatura média da massa de milho no momento do armazenamento $\left(31^{\circ} \mathrm{C}\right)$. Os resultados obtidos pelas simulações mostraram que, de duas semanas a um mês de armazenamento, a temperatura da massa de grão tende a entrar em equilíbrio com a temperatura do ar externo, e que ao final do período de armazenamento, toda a massa de milho alcançou o equilíbrio térmico. As temperaturas encontradas, tanto simuladas quanto medidas, demonstraram que a massa de grãos se mantém com temperatura média inferior a $35^{\circ} \mathrm{C}$, o que garante perdas mínimas de matéria seca do produto. Assim, pode-se concluir que o silo-bolsa é uma alternativa viável do ponto de vista da manutenção da temperatura segura para o armazenamento de milho por até quatro meses.
\end{abstract}

Palavras-chave adicionais: CFD; armazenamento; transferência de calor.

\begin{abstract}
The increase in grain production associated with the deficit in static storage capacity has forced some producers to stockpile winter corn in the open, especially in the state of Mato Grosso. The use of silo bags has become a short time alternative for traditional farm-level storage. As there are many questions regarding the storage of grain in a silo bag and the temperature behavior of the grains during storage, the objective in this work was to simulate numerically, using the technique of computational fluid dynamics (CFD), the temperature distribution of corn stored for four months in a silo bag, and to validate these data with temperature measurement in real conditions. The simulations were performed based on data of the average air temperature in the region $\left(24{ }^{\circ} \mathrm{C}\right)$ and an average of initial temperature for corn during storage $\left(31^{\circ} \mathrm{O}\right)$. The results obtained from simulations showed that from two weeks to one month's storage, the temperature of the grain mass tends to come into equilibrium with the outside air temperature and that at the end of the storage period the entire product has reached the thermal equilibrium. The founded temperatures, both from the simulation as the measurement showed that the grain mass is maintained at a temperature averaging less than $35^{\circ} \mathrm{C}$, which ensures minimal losses of dry matter of the product. Thus, it can be concluded that the silo bag is a viable standpoint to maintaining the safe temperature for corn stored to four months.
\end{abstract}

Additional keywords: CFD; storage; heat transfer. 


\section{Introdução}

A produção de grãos é um importante segmento do agronegócio brasileiro, sendo que, nos últimos anos, o Brasil destacou-se internacionalmente como grande produtor e exportador de commodities agrícolas. Porém, mesmo apresentando um desempenho produtivo expressivo, as etapas que sucedem a colheita não se desenvolveram na mesma proporção, gerando uma capacidade estática de armazenagem inferior à necessidade atual (CONAB, 2005).

A técnica de armazenamento de grãos secos em bolsas plásticas seladas hermeticamente, ou silo-bolsa, representa uma alternativa econômica aos métodos tradicionais de armazenagem, principalmente em nível de fazenda. Essa tecnologia de armazenamento permite criar uma atmosfera desprovida de oxigênio, que reduz as atividades biológicas dos organismos vivos ali presentes, proporcionando um ambiente com condições favoráveis à estocagem de produtos agrícolas (FARONI et al., 2009; FREITAS et al., 2011).

Dentre os fatores relevantes para a predição da qualidade do produto armazenado em silo bolsa está a temperatura. Uma das técnicas que permitem a análise prévia do perfil de temperatura é a dinâmica de fluidos computacional ou, como é mais conhecida, Computational Fluid Dynamics (CFD), que é uma técnica que aplica uma solução numérica das equações de transferência de calor, sob dada condição de geometria, parâmetros físicos do produto, condição inicial do mesmo e condições de contorno para o problema a ser resolvido (GASTÓN et al., 2009).

No que concerne ao armazenamento em silo-bolsa, a transferência de calor interna ocorre por condução, convecção e radiação, porém a condução é considerada o mecanismo mais relevante, em virtude da pequena quantidade de ar, em massa, presente no interior do silo e da baixa velocidade que o mesmo apresenta, acarretando, assim, ausência de correntes de convecção no interior do recipiente (RODRÍGUEZ et al., 2008). Além disso, o silo-bolsa é constituído de três películas protetoras, que possuem a função de minimizar os efeitos da radiação solar e são responsáveis pela proteção da massa de grãos contra o aquecimento (VIEIRA et al., 2006; IPESA, 2013).

Considerando também a interação do silo-bolsa com o ambiente, ocorre o processo de transferência de calor por associação dos processos de condução de calor e convecção forçada do ar externo, sendo o calor da massa de grãos difundido primeiramente para a bolsa de polietileno e, posteriormente, para a camada de ar próxima à superficie do silo, e as partículas de ar presentes nessa região apresentam uma velocidade de escoamento muito baixa em função das forças viscosas, à medida que as partículas passam para região de alta velocidade são carreadas pelo fluxo, transferindo calor para as partículas mais frias (GASTÓN et al., 2009).

Assim, neste trabalho, teve-se por objetivo simular e validar um modelo matemático para a determinação do perfil de temperatura em uma massa de milho armazenado em silo-bolsa e avaliar se esta técnica de armazenamento pode ser empregada com segurança para o produto.

\section{Material e métodos}

Dados climáticos da região:

Os dados climáticos do município de Sinop foram obtidos para o ano de 2012, entre os meses de julho e novembro, junto à estação meteorológica instalada na Universidade Federal de Mato Grosso, Câmpus de Sinop.

\section{Modelagem matemática}

Para a aplicação deste modelo, foram tomadas as seguintes considerações:

(a) Assume-se que o leito de grãos formado durante o enchimento do silo-bolsa apresenta porosidade igual à do produto armazenado em silos convencionais.

(b) No volume de controle, os grãos e o ar intergranular estão em equilíbrio térmico.

(c) A transferência de calor de massa na direção longitudinal é desprezível, comparada àquela na seção transversal do silo-bolsa. Portanto, um modelo planificado em 2D foi adotado.

(d) A redução do volume pela quebra de grãos no leito é desprezível.

(e) A taxa interna de geração de calor é desprezível, considerando a baixa taxa respiratória do produto a $11 \%$ (b.u.) de teor de água.

(f) A transferência de calor no interior do silobolsa por convecção é desprezível, assim como aquela por radiação.

\section{Geometria e condições de contorno:}

Na Figura 1, estão apresentados a geometria e o sistema de coordenadas para o silobolsa.

A geometria apresentada na Figura 1 é aquela que se aproxima da condição de um silobolsa durante o armazenamento dos grãos, ou seja, com seu volume completo de produto. A forma apresentada pelo silo nesta condição é um semicírculo, e a linha que divide o silo verticalmente em seu raio define um plano de simetria. Assim, visando a otimizar a solução numérica, foi utilizado apenas um quarto de círculo de raio igual a 1,35 m, considerando-se que os resultados encontrados neste quadrante podem ser extrapolados para o quadrante seguinte. 


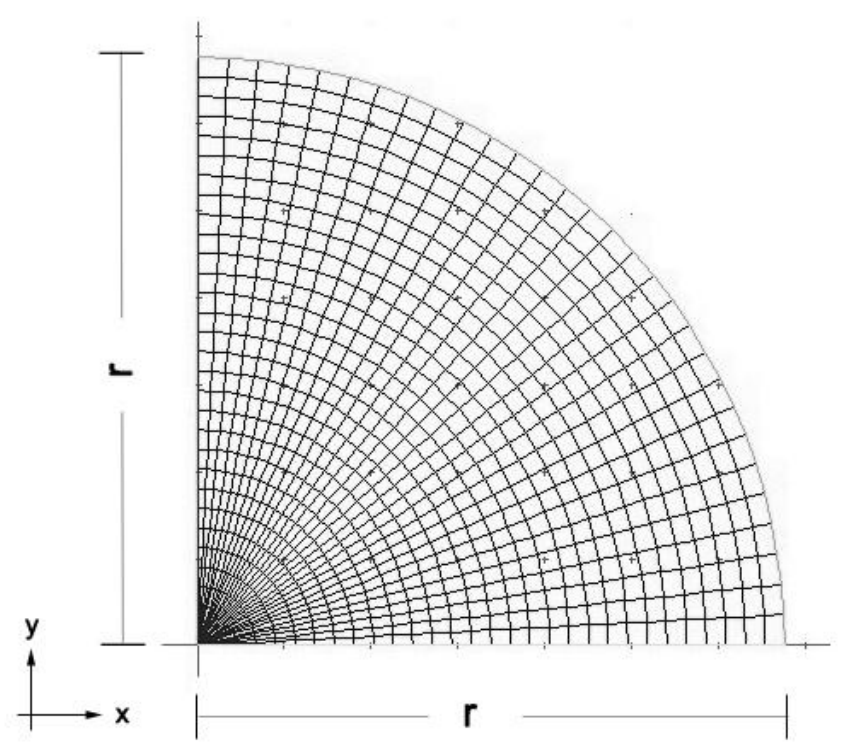

Figura 1 - Malha e sistema de coordenadas utilizadas para a solução numérica. Grid and coordinate system used to numerical solution.

A geometria apresentada na Figura 1 é aquela que se aproxima da condição de um silobolsa durante o armazenamento dos grãos, ou seja, com seu volume completo de produto. A forma apresentada pelo silo nesta condição é um semicírculo, e a linha que divide o silo verticalmente em seu raio define um plano de simetria. Assim, visando a otimizar a solução numérica, foi utilizado apenas um quarto de círculo de raio igual a $1,35 \mathrm{~m}$, considerando-se que os resultados encontrados neste quadrante podem ser extrapolados para o quadrante seguinte.

Considerando-se o raio do silo-bolsa, a malha para aplicação da solução numérica foi construída com 30 volumes em cada direção (x e $y$ ), distanciados de maneira equânime, totalizando 900 volumes diferenciais.

Nos planos representados pelos eixos $\mathrm{x}$ e $\mathrm{y}$, foi aplicada como condição de contorno a de fluxo de calor nulo. Já na face externa, foi utilizada a condição de contorno de convecção na superfície.

\section{Equações governantes:}

O modelo diferencial que governa o processo de condução de calor no silo-bolsa pode ser aproximado de um modelo bidimensional em regime transiente, onde a temperatura $T(r, \Phi, t)$ é função das coordenadas do ponto e do tempo considerado, conforme a Equação 1:

$$
\frac{1}{r} \frac{\partial}{\partial r}\left(k r \frac{\partial T}{\partial r}\right)+\frac{1}{r^{2}} \frac{\partial}{\partial \emptyset}\left(k \frac{\partial T}{\partial \emptyset}\right)+\dot{q}=\rho c_{p} \frac{\partial T}{\partial t}
$$

Em que, $\dot{q},\left(\mathrm{~W} \mathrm{~m}^{-3}\right)$, é a taxa interna de geração de calor. A condutividade térmica é denotada por $k,\left(\mathrm{~W} \mathrm{~m}^{-3} \mathrm{~K}^{-1}\right)$. O raio é denotado pelo símbolo $r$ e é dado em metros. A massa específica é denotada por $\rho\left(\mathrm{kg} \mathrm{m}^{-3}\right)$, e o calor específico, pelo símbolo $c_{p}\left(\mathrm{~J} \mathrm{~kg}^{-1} \mathrm{~K}^{-1}\right)$.

\section{Solução Numérica:}

A solução numérica do problema foi realizada através do Software CFD Studio, aplicando-se o método das diferenças finitas entre os volumes considerados.

Foram realizadas simulações numéricas para seis diferentes tempos de armazenamento da massa de grãos: 1 dia, 2 semanas, 1 mês, 2 meses, 3 meses e 4 meses.

\section{Condição inicial e propriedades físicas:}

A condição inicial foi definida apenas para a temperatura da massa de grãos, cujo valor foi obtido experimentalmente com a instalação de 9 sensores de temperatura na massa de grãos, distantes entre si $2 \mathrm{~m}$ no sentido do comprimento do silo e $0,40 \mathrm{~m}$ na altura. A temperatura observada durante os experimentos foi de $31^{\circ} \mathrm{C}$, em média.

As propriedades físicas e térmicas necessárias à aplicação do modelo foram obtidas, para o milho, segundo dados de ANDRADE et al. (2004), considerando-se o teor de água de armazenamento de $11 \%$ (b.u.). Assim, a massa específica aparente obtida foi de $727 \mathrm{~kg} \mathrm{~m}^{-3}$, condutividade térmica de $0,157 \mathrm{~W} \mathrm{~m}^{-1}{ }^{\circ} \mathrm{C}^{-1} \mathrm{e}$ calor específico de $1.737,1 \mathrm{~J} \mathrm{~kg}^{-1}{ }^{\circ} \mathrm{C}^{-1}$.

\section{Validação:}

O armazenamento do milho em silo-bolsa foi realizado no município de Sinop - MT (Latitude: $11^{\circ} 50^{\prime} 05,82$ " S; Longitude: $55^{\circ} 26$ '35,40" O), por um periodo de 4 meses, compreendendo os meses de julho a novembro do ano de 2012. 
As dimensões do silo-bolsa utilizado para validação foram: de 2,70 m de diâmetro por $6,0 \mathrm{~m}$ de comprimento e de $230-250 \mu \mathrm{m}$ de espessura. No total, foram armazenadas, aproximadamente, 32 toneladas de produto.

Os dados de temperatura para a massa de milho armazenada em silo-bolsa foram obtidos com a instalação de 9 sensores de temperatura (termopar tipo J) distribuídos de forma equânime ao longo da massa de milho armazenado. Os dados foram registrados a cada 10 minutos em um datalogger modelo Fieldlogger (Novus $\left.{ }^{\circledR}\right)$.

Análise da viabilidade do uso do silo-bolsa para o armazenamento do milho:

A análise da viabilidade técnica da aplicação do silo-bolsa para o armazenamento do milho, nas condições estudadas, foi realizada indiretamente, a partir dos diversos dados de literatura que relacionam a temperatura de armazenamento do produto com sua qualidade final.

\section{Resultados e discussão}

A análise do perfil de temperatura no interior da massa de milho armazenado no silobolsa, após decorridas as primeiras $24 \mathrm{~h}$ de armazenamento, evidenciou que a zona estável de temperatura, para as condições simuladas, atingiu apenas $135 \mathrm{~mm}$ da camada de grãos (Figura 2), sendo esta zona caracterizada pela camada de grãos que apresenta um gradiente de temperatura inferior a $4{ }^{\circ} \mathrm{C}$, conforme SILVA et al.(2008)

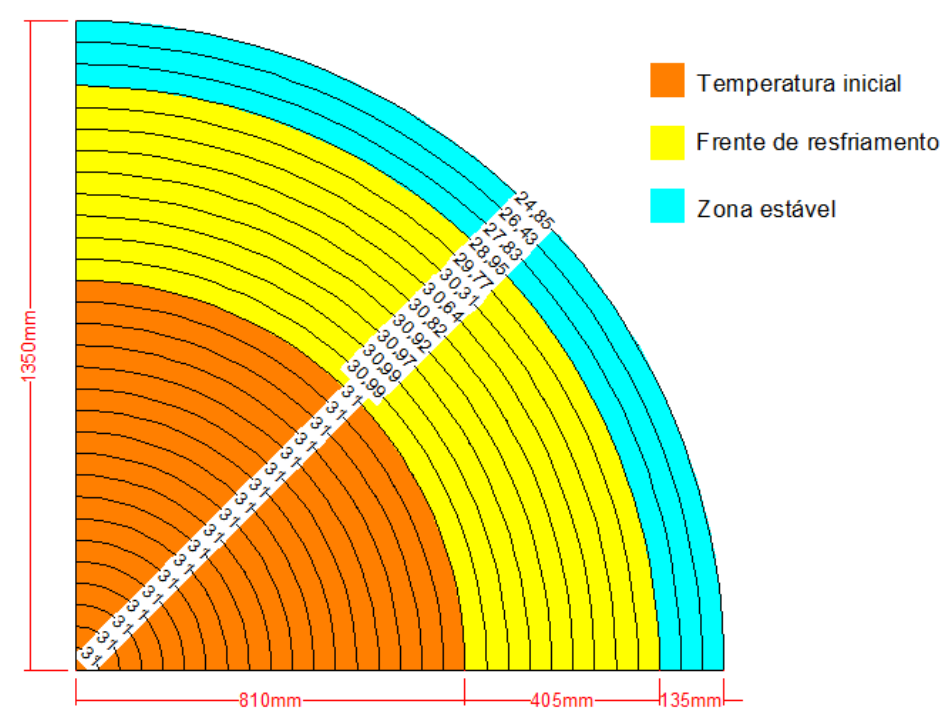

Figura 2 - Perfil da distribuição da temperatura no silo-bolsa, 24 horas após o armazenamento. Temperature profile in silo bag, 24 hours after storage.

Nesta camada específica da massa armazenada, pode-se dizer que o processo de resfriamento foi mais contundente, gerando quedas significativas na temperatura do produto. Percebe-se ainda que, devido às condições de contorno utilizadas, a camada mais externa tendeu a alcançar a temperatura ambiente $\left(24^{\circ} \mathrm{C}\right)$. Ressalta-se também que, a partir do centro, $810 \mathrm{~mm}$ de camada de grãos não sofreram ação do processo de transferência de calor, sendo este tempo insuficiente para a frente atingir tal camada. Ainda com base nos dados apresentados na Figura 2, em posição intermediária à zona estável e à camada com temperatura inalterada, caracteriza-se uma camada denomidada de frente de resfriamento, sendo aquela que apresentou leve influência do processo de transferência de calor, porém não suficiente para gerar gradiente de temperatura maior que $4{ }^{\circ} \mathrm{C}$ em relação à temperatura inicial, podendo, assim, ser considerada uniforme com relação à camada mais interna.

O tamanho da zona estável pode ser considerado pequeno quando comparado ao raio do silo-bolsa, em virtude de o tempo também ser relativamente pequeno quando comparado ao tempo total de armazenamento.

Com base nos resultados obtidos pela simulação realizada para duas semanas após o armazenamento (Figura 3), observa-se que, passado o período de duas semanas após o armazenamento, a zona estável de temperatura, para as condições simuladas, atingiu $765 \mathrm{~mm}$ da massa de grãos. $O$ resfriamente nessa zona foi promovido pela ação simultânea da condução no meio granular e da convecção do ar externo. Para esse período de armazenamento, o tamanho da zona estável de temperatura pode ser 
considerável, uma vez que a mesma atingiu mais da metade do raio do silo-bolsa. Porém, esse período de tempo mostra-se insuficiente para que a estabilidade térmica da camada total de grãos seja atingida. Nota-se também que o avanço da zona estável de temperatura no interior do silo acarretou um deslocamento da frente de resfriamento de temperatura para o centro da camada de grãos, inexistindo regiões com temperatura inicial. Isto mostra que, neste período, a transferência de calor já atingiu todo o silo.

A Figura 4 (a, b, c e d) apresenta os resultados obtidos pela simulação realizada para um mês após o armazenamento, dois meses após o armazenamento, três meses após o armazenamento e quatro meses após o armazenamento, respectivamente.

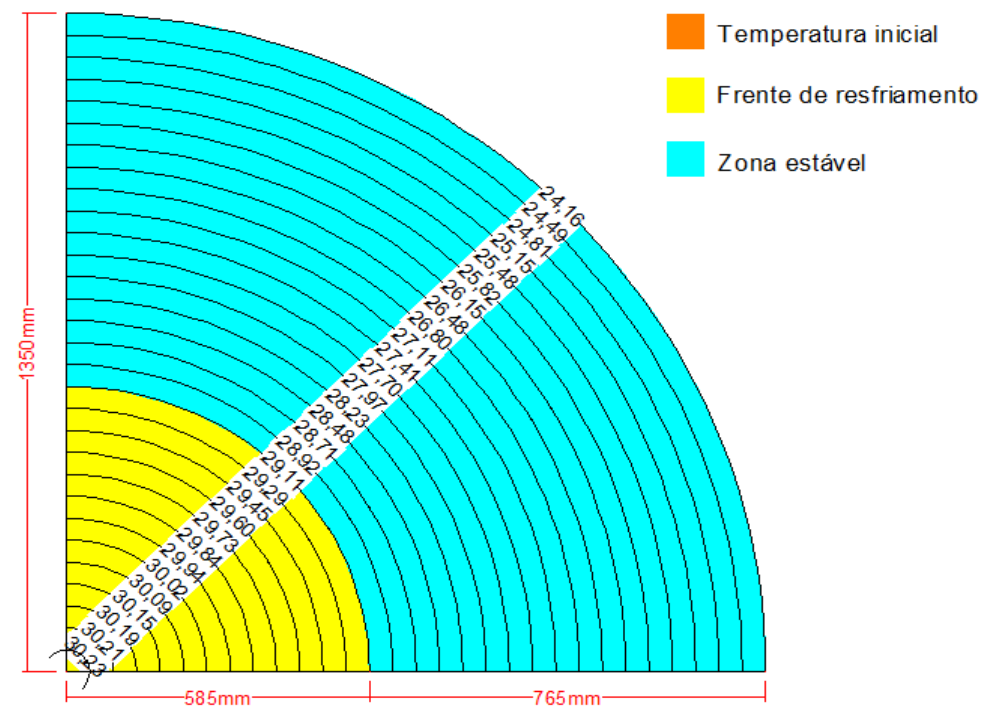

Figura 3 - Perfil da distribuição da temperatura no silo-bolsa, após duas semanas de armazenamento. Temperature profile in silo bag, 2 weeks after storage.

Por meio da análise da Figura 4a, observa-se que um mês após o armazenamento, todo o silo sofreu ação da transferência de calor, já podendo ser considerado o equilíbrio térmico do sistema, já que a maior diferença de temperatura na massa de grãos é inferior a $4^{\circ} \mathrm{C}$ (SILVA et al., 2008). É importante salientar que, no interior do silo-bolsa, as trocas térmicas ocorrem por meio do processo de condução, mesmo o produto apresentando baixa condutividade térmica.

GASTÓN et al. (2009), avaliando um modelo que prevê distribuição de temperatura em duas massas de trigo armazenadas em silobolsa, durante 150 dias, a uma temperatura inicial de armazenamento de $43,5 \stackrel{\circ}{\circ} \mathrm{C}$ com $13 \%$ b.u. e $17 \%$ b.u. de teor de água, sob condições climáticas típicas para a região de Rosário - Argentina, verificaram que os valores de temperatura medidos e simulados, para as massas, diminuíram a partir do início do armazenamento, devido à troca de calor entre o silo e o ambiente. Além disso, os autores verificaram que as mudanças de temperatura foram mais expressivas nas proximidades da zona de superfície do silo, e o centro do silo mostrou-se menos sensível às trocas térmicas com o ambiente, corroborando o comportamento da temperatura simulado neste trabalho.
Considerando-se a condição de estabilidade térmica do ar ambiente $\left(24^{\circ} \mathrm{C}\right)$ utilizado na simulação e o equilíbrio térmico do silo-bolsa atingido no 1 - mês de armazenamento, nas Figuras $4 \mathrm{~b}, 4 \mathrm{c}$ e $4 \mathrm{~d}$, observa-se a manutenção da estabilidade adquirida. Com o incremento de tempo utilizado na simulação, observa-se apenas que a diferença entre a temperatura do interior para a periferia do silo-bolsa sofreu grande redução, passando de, aproximadamente, $4{ }^{\circ} \mathrm{C}$ no primeiro mês para $0,17^{\circ} \mathrm{C}$ no quarto mês.

Com o intuito de validar o modelo simulado para transferência de calor no silo-bolsa, foram comparadas as médias dos dados experimentais medidos in loco, com as médias dos resultados gerados pelas simulações, conforme apresentado na Figura 5.

Com base na Figura 5, observa-se que, a partir do início do armazenamento até o segundo mês, as temperaturas médias medidas e simuladas diminuíram. Isto se explica pelo fato de a temperatura exterior ao silo $\left(24^{\circ} \mathrm{C}\right)$ ser inferior à do produto $\left(31^{\circ} \mathrm{C}\right)$, fazendo com que $\mathrm{o}$ processo de transferência de calor tendesse ao equilíbrio. Já, a partir do terceiro mês, para os dados medidos, houve a manutenção ou o aumento da temperatura, isto em virtude de a temperatura externa ter sido um pouco mais ele- 
vada, mudando o sentido da transferência, que até o momento era do grão para o ar externo e passou a ser do ar externo para o grão, evidenciando um processo de aquecimento da massa. Observa-se ainda que, para os diferentes tempos simulados, as temperaturas médias simuladas e as temperaturas médias medidas apresentam um comportamento análogo em quase todos os pontos (superficial, médio e inferior), com exceção do ponto médio medido, que apresenta valores discrepantes de temperatura quando comparado com os valores medidos superficial e inferior.

LASZLO \& ADRIAN (2009) ajustaram um modelo que descreve a distribuição da temperatura em uma massa de grãos de trigo, armazenada em silo metálico durante 18 meses, a uma temperatura inicial de armazenamento de $22{ }^{\circ} \mathrm{C}$ com $13,5 \%$ b.u. de umidade, sob condições climáticas da região de Oradea - Roménia. Os autores também observaram, por meio de comparações dos resultados simulados com os dados experimentais, que ambos tenderam a um comportamento similar. GASTÓN et al. (2009) validaram um modelo que prediz a evolução da temperatura em duas massas de trigo armazenadas em silo-bolsa, sob influencia da variação sazonal do clima da região de Buenos Aires Argentina. $\mathrm{O}$ produto foi estocado com temperatura de $43,5{ }^{\circ} \mathrm{C}$ e umidades de $12,5 \%$ b.u. e $16,4 \%$ b.u., durante 150 dias. Verificaram que os resultados simulados se mostraram de acordo com os dados medidos experimentalmente.

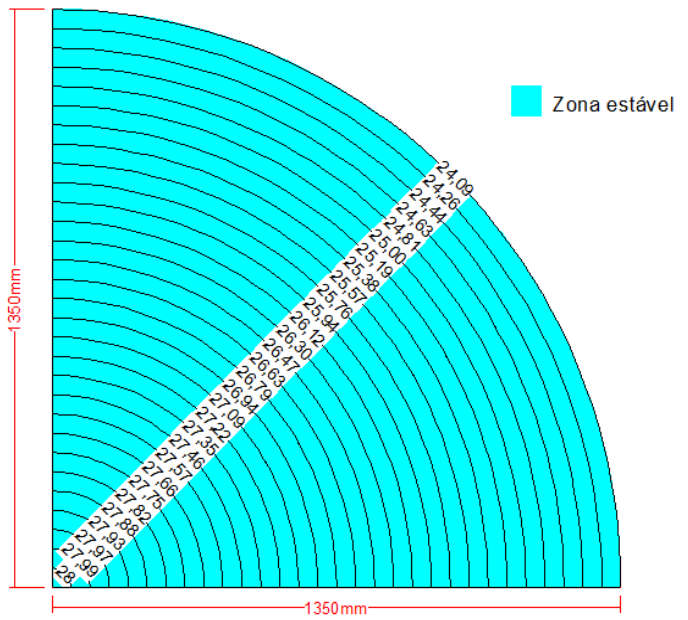

(a)

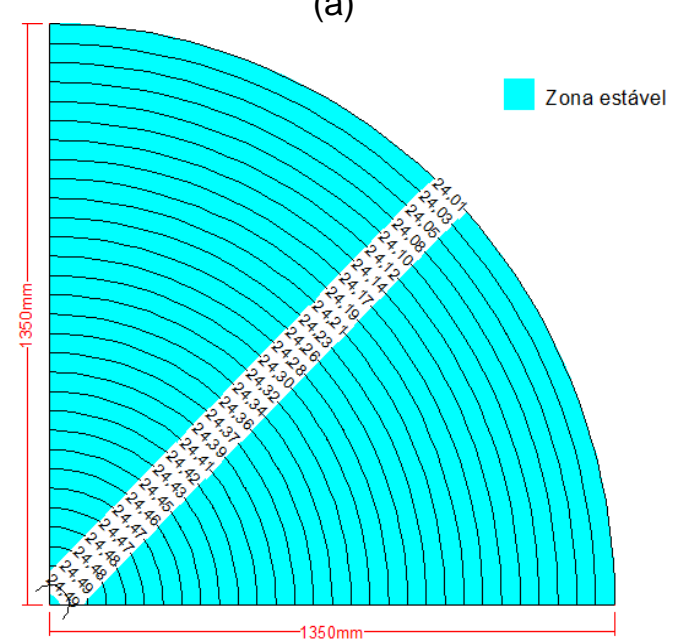

(c)

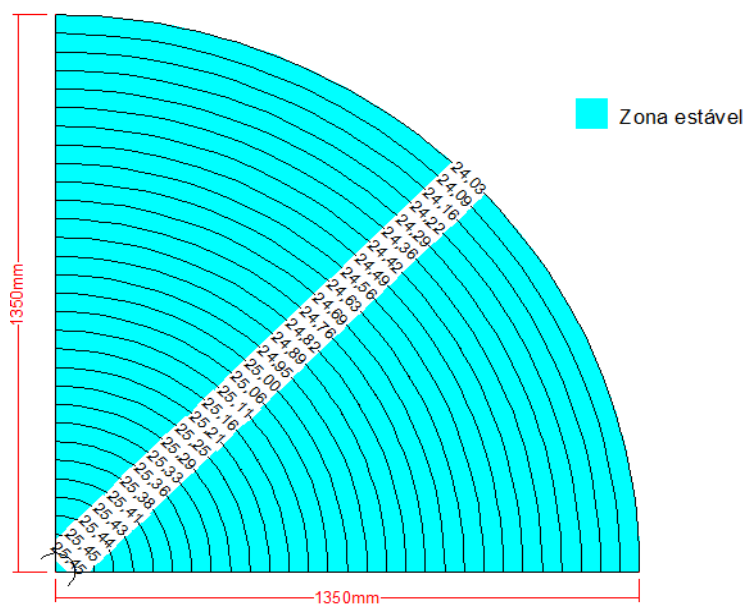

(b)

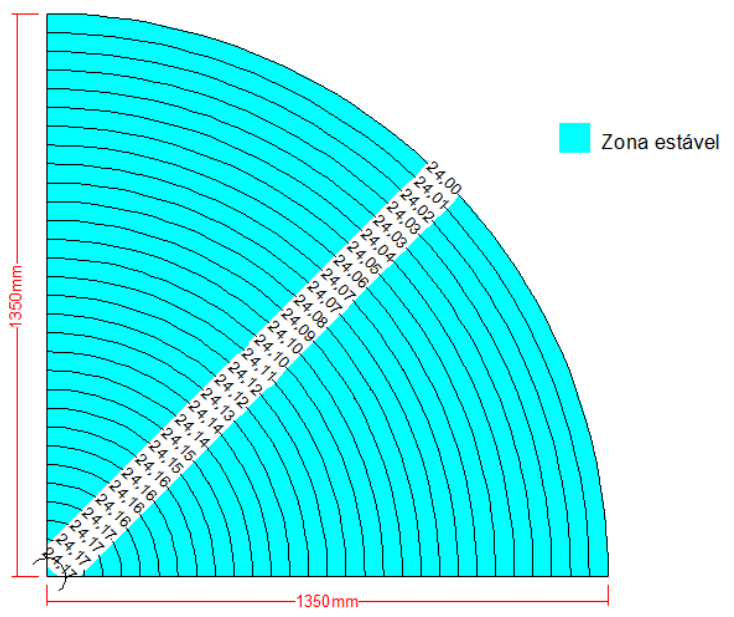

(d)

Figura 4 - Perfil da distribuição da temperatura no silo-bolsa, após: (a) um mês de armazenamento; (b) dois meses de armazenamento; (c) três meses de armazenamento, e (d) quatro meses de armazenamento. Temperature profile in silo bag, after: (a) one month of storage; (b) two months of storage; (c) three months of storage; (c) four months of storage. 


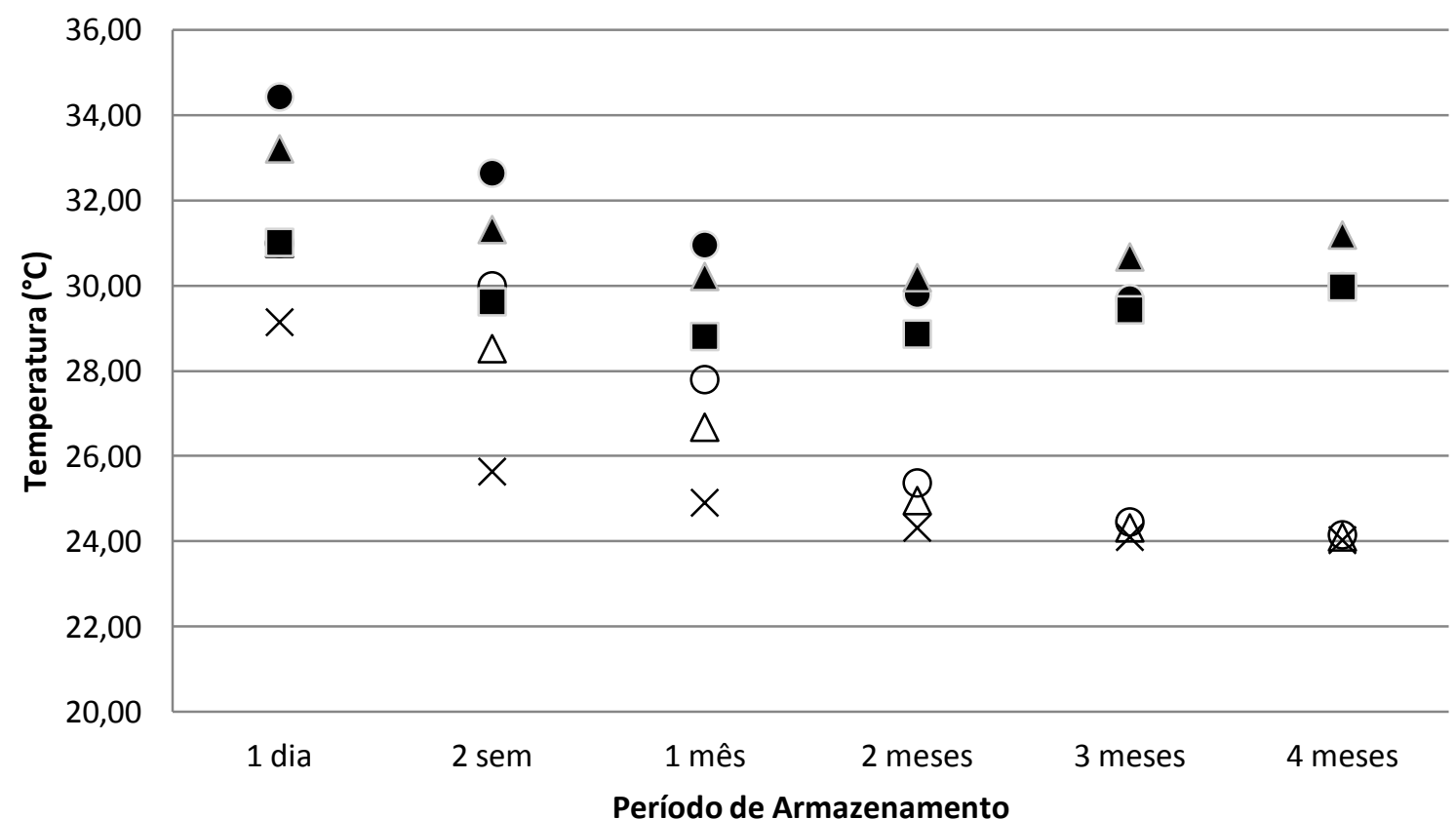

O inferior simulado $\Delta$ médio simulado $\times$ superficial simulado $\bullet$ inferior medido $\Delta$ médio medido $\square$ superficial medido

Figura 5 - Temperaturas médias medidas e simuladas no interior do silo-bolsa. Means for measured and simulated temperature inside the silo bag.

Ainda com base na Figura 5, nota-se que, após duas semanas de armazenamento, a massa de grãos já apresenta características de ter atingido o equilíbrio térmico com o ar ambiente, tanto para os dados medidos quanto para os simulados, considerando-se diferenças inferiores a $4{ }^{\circ} \mathrm{C}$ como sendo uniformes, conforme SILVA et al. (2008).

Por fim, a partir dos dados medidos de temperatura no silo-bolsa para a massa de milho armazenado, verificou-se que a temperatura máxima atingida pelo produto foi de $34,4{ }^{\circ} \mathrm{C}$, o que confere boa manutenção da qualidade final do produto ao término do período de armazenamento, já que a temperatura é um dos principais fatores físicos responsáveis pela deterioração dos grãos ao longo do armazenamento (SANTOS et al., 2004). COSTA et al. (2010), ao analisarem a qualidade de grãos de milho armazenados em silo-bolsa, verificaram que grãos armazenados com umidade de até $14,5 \%$ b.u. podem ser armazenados hermeticamente com temperatura de $35{ }^{\circ} \mathrm{C}$ por até 180 dias, sem alteração na classificação do produto. SANTOS et al. (2010), estudando a qualidade de milho armazenado em bolsas herméticas após tratamento com Isotiocianato de alila, também verificaram que o armazenamento de milho por até 150 dias, com temperatura de $35^{\circ} \mathrm{C}$, é eficiente em manter a qualidade do produto bem como em garantir o controle do crescimento de fungos.

\section{Conclusões}

O modelo de condução transiente utilizado para descrever a distribuição de temperatura no interior do silo-bolsa ajustou-se bem à condição de armazenamento estudada, simulando valores de temperatura próximos àqueles medidos durante a validação.

Sob a óptica da manutenção da temperatura segura para o armazenamento de milho, por até quatro meses, o silo-bolsa é uma técnica viável, considerando-se que a massa de grãos se mantém com temperatura média inferior a $35^{\circ} \mathrm{C}$.

\section{Agradecimentos}

Ao ADM Institute pelo suporte financeiro, À IPESA Silos pelo apoio técnico e concessão de material para a pesquisa e ao Senhor Jadir Taffarel pela concessão do produto e pela cessão do espaço para instalação do silo bolsa.

\section{Referências}

ANDRADE, E. T.; COUTO, A. M.; QUEIROZ, D. M.; PEIXOTO, A. B. Determinação de propriedades térmicas de grãos de milho. Ciência e Agrotecnologia, Lavras, v.28, n.3, p.488-498, 2004. 
CONAB - Companhia Nacional de Abastecimento. Armazenagem no Brasil, Brasília, 2005. Disponível em: <http://www.conab.gov.br/OlalaCMS/uploads/arq uivos/7420aabad201bf8d9838f446e17c1ed5.pdf >. Acesso em: 17.maio.2013.

COSTA, A. R.; FARONI, L. R. D.; ALENCAR, E. R.; CARVALHO, M. C. S.; FERREIRA, L. G. Qualidade de grãos de milho armazenados em silo bolsa. Revista Ciências Agronômicas, Fortaleza, v.41, n.2, p.200-207, abr.-jun.2010.

FARONI, L. R. D; ALENCAR E. R.; PAES, J. L; COSTA, A. R.; R. R.C.C. Armazenamento de soja em silo tipo bolsa. Engenharia Agrícola, Jaboticabal, v.29, n.1, p.193-201, jan./mar.2009.

FREITAS, R. S.; FARONI, L. R. D.; SOUSA, A. H.; CECON, P. R.; CARVALHO, M.S.. Quality of beans stored under hermetic conditions. Engenharia Agrícola, Jaboticabal, SP, v.31, n.6, p.1136-1149, nov./dez. 2011.

GASTÓN, A.; ABALONE, R.; BARTOSIK, R. E.; RODRÍGUEZ J. C. Mathematical modelling of heat and moisture transfer of wheat stored in plastic bags (silobags). Biosystems Engineering, London, v.104, n.01, p.72-85, 2009.

IPESA. Características técnicas das bolsas IpesaSilo ${ }^{\circledR}$ 2013. Disponível em: <http://www.ipesadobrasil.com.br/novo/asp/listage m.asp?id=2eidsub=58etipo=3>. Acesso em: 25 jul. 2013.

LASZLO, R.; ADRIAN, T. Simulation of changes in a wheat storage bin regarding temperature. Annals of Faculty of Environmental Protection, University of Oradea, Faculty of Environmental Protection. v.14, p.237-244, 2009.
RODRÍGUEZ, J. C.; BARTOSIK, R. E.; CARDOSO M. L.; CROCCE, D. Factors affecting carbon dioxide concentration in interstitial air of wheat stored in hermetic plastic bags (silo-bag). In: The Proceedings of the 8th International Conference on Controlled Atmosphere and Fumigationin Stored Products, Chengdu, China, 2008. 7p.

SANTOS, C.M.R., MENEZES, N. L.:VILLELA, F.A. Alterações fisiológicas e bioquímicas em sementes de feijão envelhecidas artificialmente. Revista Brasileira de Sementes, Viçosa, MG, v.26, n.1, p.110-119, 2004 ..

SANTOS, S. B.; MARTINS, M. A.; FARONI, L. R. D.; RODRIGUES JUNIOR, V.; DHINGRA, O. D. Quality of maize grains treated with allyl isothiocyanate stores in hermetic bags. Journal of Stored Products Research, Oxford, v. 46, n.2, 2010, p.111-117

SILVA, J. S.; LACERDA FILHO, A. F.; DEVILLA, I. A.; LOPES, D. C.. Aeração de grãos armazenados. In: SILVA, J. S. Secagem e armazenagem de produtos agrícolas. 2.ed. Viçosa, MG: Aprenda Fácil, 2008. p.269-295

VIEIRA, E. H. N.; BASSINELLO, P. Z.; MELO, L. C.; MOREIRA, G. A.; PEIXOTO, D.; GLODER, E. L. Avaliação da qualidade tecnológica do feijão armazenamento em silo bolsa. Santo Antônio de Goiás: Embrapa Arroz e Feijão, 2006. $4 p$. (Comunicado Técnico/Recomendações Técnicas, 116). 